\title{
How female physicians are supporting each other in addressing professional inequities
}

\author{
口 Cite as: CMAJ 2019 April 29;191:E485-6. doi: 10.1503/cmaj.109-5740
}

Posted on cmajnews.com on Apr. 11, 2019.

W ith the launch of Time's Up Health Care, the discrimination women face in medicine, from the gender pay gap to harassment to leadership barriers, is more visible than ever. What's less known is how women are surviving in their sometimes toxic work environments, and how they're pushing back to address system inequities.

One key, and simple, strategy is to demand the doctor title. Dr. Justine Amaro, an emergency physician and assistant professor at the University of Ottawa, warns female trainees against going by their first names. "There is no room for you to be casual," she tells them. "You need to say, 'I'm Dr. So-andso,' loudly and confidently." Many female doctors have written about being mistaken frequently for non-MD health care staff, and a recent study found that women physicians are less likely to be introduced with the doctor title by peers.

Women are also devising ways to give each other's voices more weight in medical leadership meetings. Dr. Kim Kelly, a family doctor and board member of the Alberta Medical Association, says women on her board use the "amplification" technique. "When a female board member states something that is ignored, we repeat it, we draw attention to it, and we make sure the speaker gets credit for it," she says, noting that the technique was popularized by female aides in the White House.

At a national level, Kelly is the lead sponsor of a Canadian Medical Association community of interest on creating an inclusive and equitable medical community. "We're educating members on why harassment and the gender pay gap and the lack of women in leadership continues," she says, noting the need for more transparent data from medical associations on gender breakdowns in leadership categories. "We're hoping to provide a wiki page for best practices to advance women in leadership, to provide a safe place for discussion, and to create mentor-mentee relationships."

Organizations that advocate on behalf of female physicians are not new. The Federation of Medical Women in Canada

\begin{abstract}
"Morale was really low amongst women [physicians] over social media, and I thought it would be interesting to get people together. I was overwhelmed with responses," she says.

She reached out to other leaders and planned a conference. The group will host its second annual conference in June, with talks on topics such as imposter syndrome and dealing with social media
\end{abstract}

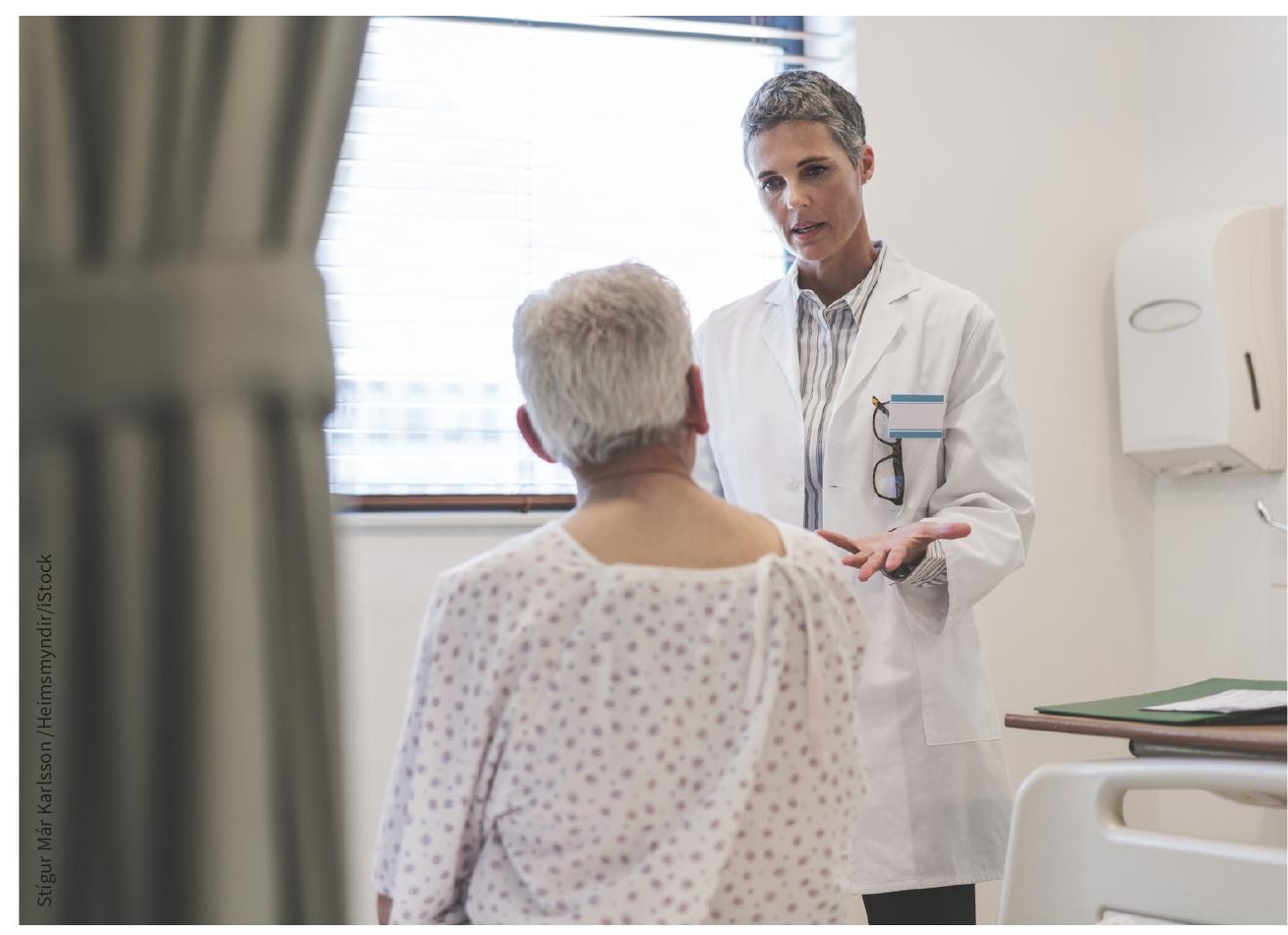

Female doctors should always introduce themselves with the Dr. title, recommend some women leaders in medicine.

has been working to advance female MDs since 1924. But in recent years, a number of new groups have joined the fray.

Canadian Women in Medicine was launched by Dr. Setareh Ziah after a colleague, Dr. Elana Fric, was murdered by her husband, who was also a doctor. trolls. "There is this need for women in medicine to validate each other, to lift each other up," she says.

The group also engages in advocacy, intervening when women taking medical licensing exams were asked to declare menstrual products, and in the case of an 
emergency department chief who hadn't hired a woman in 16 years.

Female doctors are engaging their male peers, too. Dr. Mamta Gautam, a psychiatrist and physician-executive coach, is running a workshop at the upcoming Canadian Conference on Physician Leadership for male physicians who want to be better allies to female colleagues.

"Part of it is just raising the awareness of the implicit bias that both men and women have and providing the data on how that affects women in medicine," she says.

Gautam's workshop aims to help physicians become more attuned to incidents when women are passed over for mentorship or leadership positions and will offer advice on how male doctors can intervene when necessary. "Often the men in the room have had experiences of hearing a comment like, 'She's going to be off again on mat leave, so why should we take her into this role?" says Gautam. "When you say nothing, you're permitting these attitudes."
Gautam has been running leadership workshops for female physicians for seven years, and recently announced the launch of a think tank on advancing women leaders. "Different medical organizations have been working to advance women leaders for many years, but there are limitations to what they do," she says. "What I see in the States, and increasingly here, are groups of women saying: 'We're going to stand up and do this ourselves."'

Wendy Glauser, Toronto, Ont. 